\title{
Andalabs: conectando la innovación ciudadana en Andalucía
}

\begin{abstract}
La Red de Laboratorios Ciudadanos de Andalucía nace en mayo de 2017 de la mano de Medialab UGR, perteneciente a la Universidad de Granada, con la intención de conectar la innovación ciudadana que se desarrolla en Andalucía en sus diversas formas. AndaLabs centra su atención en la pluralidad de espacios físicos y/o digitales, híbridos, que sirven de cauce a la innovación social y ciudadana, y en la integración del conocimiento plural distribuido en la sociedad, otorgando el papel protagonista a la ciudadanía.
\end{abstract}

Esteban Romero Frías | director de Medialab UGR

URL de la contribución <www.iaph.es/revistaph/index.php/revistaph/article/view/3969>

Se trata de un enfoque que busca integrar el conocimiento distribuido en la sociedad para el desarrollo de proyectos de transformación co-creados por una pluralidad de actores sociales, destacando el papel protagonista de la ciudadanía.

En la denominación de la red, "Anda" no sólo hace referencia a la perspectiva andaluza, sino que hace una llamada a "moverse", a una puesta en marcha de la sociedad que, desde lo público, lo privado, los movimientos sociales y la ciudadanía, actuando de forma colectiva o individual, se activa para diseñar su futuro de manera experimental, inclusiva, colaborativa y abierta.

El objetivo principal de la red Andalabs (http://andalabs.org/) es constituir un instrumento para el impulso de un sistema de innovación social y ciudadana, para el territorio y desde el territorio (ciudades y pueblos) en Andalucía. La Red pretende funcionar como un instrumento de integración y fortalecimiento de las iniciativas ya existentes y de aquellas que emergen. Si nos centramos en el ámbito público, se parte del reconocimiento de iniciativas que ya están en marcha, por ejemplo, iniciativas de innovación social que se desarrollan en algunos centros Guadalinfo (www.guadalinfo.es) en poblaciones con menos de 20.000 habitantes, o iniciativas que emergen en el seno de instituciones ya consolidadas como podría ser el caso del Laboratorio Abierto de Patrimonio en el Instituto Andaluz del Patrimonio Histórico.

Una de las necesidades que la iniciativa Andalabs pretende resolver es la articulación de iniciativas que comparten una serie de valores, intereses y problemáticas en común, con independencia de su origen en lo público, lo privado o los movimientos sociales, de su aparición en pequeños o grandes núcleos urbanos, o de su surgimiento como entidades nuevas o como espacios de transformación dentro de organizaciones ya asentadas.

Un primer paso para conseguir esto es mapear las iniciativas que tienen lugar principalmente en Andalucía pero no de forma excluyente ya que también podrían incorporarse casos de otras partes del territorio español o internacionales, con particular interés en el ámbito latinoamericano y europeo, siempre que manifiesten un interés por conectarse con el ecosistema andaluz de innovación ciudadana.

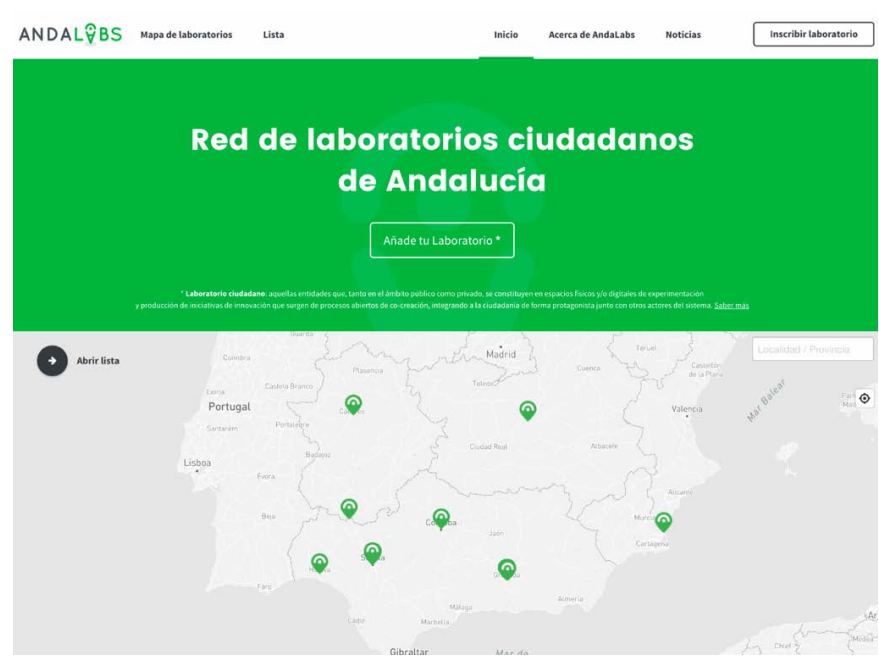




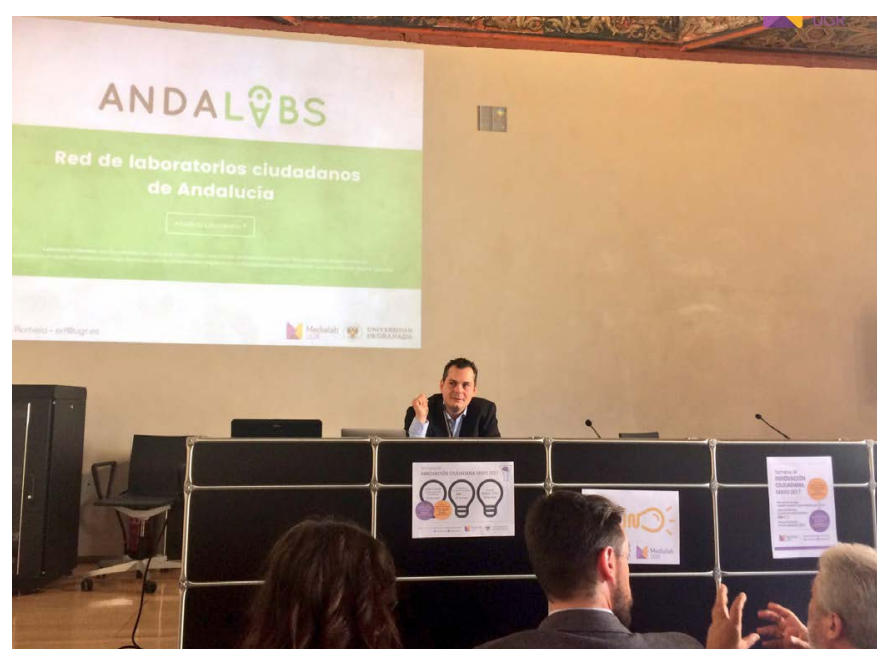

Acto de presentación de la red Andalabs | foto Alejandra Ramírez

La actual plataforma digital, en su primera fase, permite completar un formulario online con la información más relevante del laboratorio, proporcionando acceso a sus páginas webs y perfiles en redes sociales. Los laboratorios se muestran geolocalizados a través de un mapa que facilita la navegación y el descubrimiento de los mismos. Se incluye además un espacio para la publicación de noticias y eventos.

La presentación de Andalabs se realizó en el marco de la Semana de la innovación ciudadana (http://medialab. ugr.es/noticias/una-semana-para-la-innovacion-ciudadana-en-granada/) celebrada en Granada del 24 al 26 de mayo de 2017. El día 26 de mayo se dedicó a un primer encuentro ligado a Andalabs en el que diversos grupos involucrados dentro de la red pudieron expresar sus diagnósticos, intereses, expectativas e ideas para continuar el trabajo.

Entre las necesidades identificadas destaca principalmente la generación de redes que, por medios digitales, sirvieran de germen para encuentros presenciales posteriores. Se coincidió también en solicitar un mayor apoyo desde lo público, que es desde donde se deberían incentivar estas iniciativas ciudadanas de carácter transversal. Fue también intenso el debate sobre la propia naturaleza de los denominados laboratorios ciudadanos y sobre cuáles serían sus características defini- torias. Todo ello son cuestiones que desde Andalabs se abordarán de manera abierta y consensuada.

La red Andalabs no es una iniciativa aislada en el entorno español. Cabe destacar que desde finales del año 2016 la Generalitat de Catalunya impulsa la red CatLabs (http://catlabs.cat) que justamente pretende convertirse en una parte fundamental del sistema de innovación catalán, reconociendo la importancia del pilar ciudadano y social dentro de un modelo de transferencia de conocimiento de cuádruple hélice.

La comunidad andaluza tiene la oportunidad de liderar este enfoque de innovación en nuestro país, tendiendo puentes con Latinoamérica y África a través de los potentes programas de cooperación que desarrolla la Junta de Andalucía, así como activando el potencial de la participación ciudadana para crecer también en innovación.

Próximamente desde Andalabs se organizará un encuentro que permita estrechar lazos entre la comunidad, consensuar definiciones y principios y esbozar proyectos de futuro. 